\title{
Proceeding
}

Supplementary Issue: Rio 2016 Olympic Games Fourth Anniversary Special Edition. Olympic Studies Forum, 21-24 October 2020. Olympic Studies Research Group, Pontifical Catholic University of Rio Grande do Sul (GPEO PUCRS), Brazil

\section{Values and education: The Olympic education program in Portugal}

\section{Valores e educação: 0 programa de educação olímpica em Portugal}

\author{
RITA AMARAL NUNES \\ Faculty of Social and Human Sciences, Nova University, Lisboa, Portugal
}

\begin{abstract}
The aim of this work is to make known the Olympic Education Program (PEO) that has been implemented in Portugal, since 2015, by the Olympic Committee of Portugal (COP). Based on an analysis of the experiences and implementation of similar programs in other countries, in particular the Olympic Values Educational Programme (OVEP), developed by the International Olympic Committee (IOC), an Olympic Education Program was created following international orientations and good practices experiences. In addition to these contributions, it was considered to implement and develop new content aiming at facilitating daily activities carried on by teachers and educators in Portuguese teaching institutions; themes such as the Portuguese participation in the summer and winter Olympic Games, Olympic Medallists or Portuguese Olympic Champions, were addressed. In order to respond to new challenges faced by schools due to the emergence of the COVID-19 pandemic, the activities implemented in 2020 are also discussed, they aimed to make the Olympic Education Program more flexible and dynamic, by making available, online, new sets of contents and activity proposals.
\end{abstract}

Keywords: Olympism; Education; Values; Olympic education.

\section{Cite this article as:}

Nunes, R.A. (2021). Values and education: The Olympic education program in Portugal (in Portuguese). Journal of Human Sport and Exercise, 16(1 proc), S92-S105. doi:https://doi.org/10.14198//hse.2021.16.Proc1.09

Corresponding author. Faculty of Social and Human Sciences, Nova University, Lisboa, Portugal. http://orcid.org/0000-0002$\underline{3451-3256}$

E-mail: itaa.nunes@gmail.com

Supplementary Issue: Rio 2016 Olympic Games Fourth Anniversary Special Edition. Olympic Studies Forum, 21-24 October 2020. Olympic Studies Research Group, Pontifical Catholic University of Rio Grande do Sul (GPEO PUCRS), Brazil.

JOURNAL OF HUMAN SPORT \& EXERCISE ISSN 1988-5202

(c) Faculty of Education. University of Alicante

doi:10.14198/jhse.2021.16.Proc1.09 


\section{RESUMO}

O objetivo deste trabalho é dar a conhecer o Programa de Educação Olímpica (PEO) que vem sendo implementado em Portugal, pelo Comité Olímpico de Portugal (COP), desde 2015. Partindo de uma análise das experiências e dos Programas existentes ao nível da implementação da Educação Olímpica noutros países, bem como, do Programa de Educação em Valores Olímpicos (OVEP) lançado pelo Comité Olímpico Internacional (COI), foi construído um Programa de Educação Olímpica que reúne as orientações internacionais e as experiências e boas práticas de alguns Programas implementados por outros Comités Olímpicos nacionais e Comités Organizadores de Jogos Olímpicos. Para além destes contributos, considerou-se importante o desenvolvimento de conteúdos próprios que pretendem facilitar o trabalho diário desenvolvido pelos professores e educadores nos Estabelecimentos de Ensino portugueses, aprofundando temáticas como a participação portuguesa nos Jogos Olímpicos de verão e de inverno, os Medalhados Olímpicos e os Campeões Olímpicos portugueses. Perante os novos desafios que as escolas enfrentam, decorrentes do surgimento da Pandemia COVID-19 serão também apresentadas as iniciativas que foram implementadas ao longo do ano de 2020, de forma a tornar o Programa de Educação Olímpica mais ágil e dinâmico, colocando à distância de um clique, um conjunto renovado de conteúdos e propostas de atividades.

Palavras-Chave: Olimpismo; Educação; Valores; Educação Olímpica. 


\section{INTRODUÇÃO}

0 mundo está a mudar a uma velocidade sem precedentes. Atualmente, questões relacionadas com a educação, a saúde física e mental, a economia, a multiculturalidade, a tolerância e o respeito, os direitos humanos, o meio ambiente, a superação e a resiliência aos novos desafios que somos submetidos diariamente, fazem parte do quotidiano da maioria da população mundial. Estas mudanças que ocorrem como resultado da globalização também afetaram, inevitavelmente, o comportamento dos jovens e o seu processo educativo. Torna-se assim necessário robustecer a educação, valorizando a importância dos valores, como pilares essenciais para um processo educativo de sucesso. 0 desporto, à semelhança de outros contextos, como 0 académico, possibilita a exposição das crianças e jovens a experiências específicas que, vivenciadas da forma correta, vão potenciar o desenvolvimento de competências como a autoconfiança, o respeito, a resiliência e a autonomia, entre outras. Consequentemente, ao verem elevadas as suas competências de base, estarão melhor preparados para encontrar soluções mais ajustadas face aos desafios que lhes são colocados diariamente, no plano da prática desportiva, mas também nas suas vidas.

Desta forma, o desporto foi reconhecido como uma ferramenta poderosa de aprendizagem para a educação, fornecendo uma linguagem universal para transmitir mensagens-chave sobre as questões de estilos de vida saudáveis, inclusão social, igualdade de género e reconstrução de comunidades locais. (COI, 2016b, p.8).

Em Portugal, no âmbito da visão, que o Comité Olímpico de Portugal definiu para o seu mandato que se iniciou em 2013, de "Valorizar Socialmente o Desporto", surgiu dois anos mais tarde, em 2015, o Programa de Educação Olímpica com o objetivo de contribuir para a formação dos jovens em contexto escolar, dos diversos níveis de ensino, através da transmissão de conhecimentos e competências, onde o Olimpismo, os Jogos Olímpicos, os Atletas Olímpicos, o gosto pela prática desportiva e os hábitos de vida saudável, são usados como ferramentas educativas e exemplos de superação, motivação e resiliência, realçando-se a importância que os Valores Olímpicos: EXCELÊNCIA, AMIZADE e RESPEITO, têm não só em ambiente desportivo, mas no dia-a-dia.

É interessante verificar que Pierre de Coubertin, desde os primeiros dias do Movimento Olímpico moderno promoveu o valor educativo e social do desporto, designando-o como "Educação Desportiva". Para Coubertin o caráter dos jovens podia ser desenvolvido através da experiência individual proporcionada pela atividade desportiva e daí tornar-se transversal para a vida como um todo. (CEO, 2020) 0 termo "educação olímpica" apenas surgiu nos anos 70 do século XX nas áreas da educação e da investigação, tendo 0 primeiro Programa de Educação Olímpica sido implementado em 1972, por ocasião dos Jogos Olímpicos de Munique (Georgiadis, 2010, p.6711). 0 exemplo da Alemanha foi seguido pelo Comité Organizador dos Jogos Olímpicos de Montreal que durante os anos letivos de 1973 a 1976, implementou nas escolas de Québec, o programa designado "Promover o Olimpismo em Ambiente Escolar" que teve como principal objetivo promover uma compreensão mais ampla do Movimento Olímpico e seu impacto na sociedade moderna. (Georgiadis, 2010, p.6711).

Historicamente, pode assim considerar-se que estas foram as primeiras iniciativas e os primeiros exemplos de boas práticas do que, hoje em dia, muitos Comités Olímpicos Nacionais e Comités Organizadores dos Jogos Olímpicos desenvolvem nos seus países com o propósito de inspirar e conscientizar os jovens em idade escolar e por inerência as suas famílias, para a importância de atitudes e valores positivos como a cooperação, a capacitação, o pensamento crítico, a criatividade, a responsabilidade e o respeito, entre tantos outros. 
O termo "Educação Olímpica" é definido por Norbert Muller, um dos maiores especialistas nesta área, como um conceito que assenta no desenvolvimento humano holístico, ou seja, "A 'Educação Olímpica' esforça-se para fornecer uma educação universal ou desenvolvimento de todo o indivíduo humano, em contraste com a educação cada vez mais especializada encontrada em muitas disciplinas especializadas. Consequentemente, ela só pode ser baseada nos valores fundamentais da personalidade humana". (Muller, 2010, p.5)

No entanto, se recuarmos às origens do Movimento Olímpico, verificamos que desde a sua constituição, 0 Comité Olímpico Internacional tem dedicado uma atenção especial e estratégica à Educação. Esta dedicação é, desde logo, entendida porque Pierre de Coubertin, reconhecido pedagogo francês e fundador dos Jogos Olímpicos da era moderna teve como objetivo, após a humilhante derrota da França na Guerra Franco-Prussiana de 1870/71, dar o seu contributo para reerguer o seu país. Foi com este sentimento que o barão de Coubertin se convenceu que a melhor forma de contribuir para esta causa seria através da reforma educativa francesa.

Ao ter conhecimento de outros modelos educativos, nomeadamente o britânico e o norte americano, da existência de festivais desportivos, como os Wenlock Olympian Games, os Zappas Games e os Panhellenic Games, e das descobertas arqueológicas em Olímpia, lideradas pelo alemão Ernst Curtius, que em 1881 permitiram o início da reconstituição da cidade-estado, onde tinham sido realizados os Jogos Olímpicos, entre 0 ano de 776 a.C. e 393 d.C, que Pierre de Coubertin, não só trabalhou para concretizar, em 1890, a reforma educativa de França com a inclusão da educação física e das práticas desportivas, como também, diligenciou todos esforços e ações necessárias com vista a concretizar o seu sonho de reorganizar os Jogos Olímpicos.

Assim, a 25 de novembro de 1892, por ocasião das celebrações do cinquentenário da Union des Sociétés Française de Sports Athlétics - USFSA, realizadas na Universidade de Sorbonne, Pierre de Coubertin, decidiu lançar pela primeira vez a sua ideia de organizar os Jogos Olímpicos (Chatziefstathiou \& Henry, 2012, p.84). Esta sua ideia, à data, não reúne os apoios necessários o que faz com que Pierre de Coubertin continuasse a trabalhar no seu sonho para, em junho de 1894, voltar a relançá-lo. Foi por ocasião do Congresso Internacional de Educação Física, realizado na mesma universidade, que à última hora Coubertin decide rebatizar de "Congresso para o Restabelecimento dos Jogos Olímpicos" que, a 23 de junho de 1894, é aprovada por unanimidade e aclamação, por 79 representantes de universidades, professores, membros de federações desportivas e higienistas, oriundos de 13 países, a proposta de Coubertin para 0 restabelecimento dos Jogos Olímpicos (Ferreira, DaSilva \& Afonso, 1996, p.10). É também neste dia, 23 de junho de 1894, que é constituído o Comité Olímpico Internacional (COI), entidade que ficaria encarregue de organizar os Jogos Olímpicos da era moderna. Note-se, a este respeito, que desde 1948, o dia 23 de junho, é celebrado e reconhecido em todo o mundo, como o Dia Olímpico (Nunes \& Videira, 2020, p.13).

Pierre de Coubertin tinha uma ideia muito estruturada e desenvolvida do que pretendia para o Movimento Olímpico. A este respeito redigiu, em 1898, a primeira Carta Olímpica, um documento que define a codificação dos Princípios Fundamentais do Olimpismo, as regras e os estatutos adotados pelo COI, e que, com as devidas atualizações, ainda hoje existe. É precisamente no primeiro Princípio Fundamental do Olimpismo, definidos na atual versão da Carta Olímpica, publicada e em vigor desde 17 de julho de 2020, que encontramos a ligação entre os três pilares do Olimpismo: Desporto, Cultura e Educação:

"O Olimpismo é uma filosofia de vida que exalta e combina, de forma equilibrada, as qualidades do corpo, da vontade e da mente. Aliando o desporto à cultura e à educação, o Olimpismo procura criar 
um estilo de vida baseado na alegria do esforço, no valor educativo do bom exemplo, na responsabilidade social e no respeito pelos princípios éticos fundamentais universais." (COI, 2020b, p.11).

A este propósito podemos verificar que mesmo antes da transferência da sede do COI de Paris para Lausanne, que ocorreu a 10 de abril de 1915, devido à eclosão da Primeira Guerra Mundial, Pierre de Coubertin tinha já manifestado o seu desejo de criar um Museu Olímpico e uma Biblioteca em Lausanne. (Morath, 2012, p.15).

No entanto, o grande impulso na área da Educação Olímpica dá-se com a criação da Academia Olímpica Internacional (AOI). Esta ideia surgiu, em 1938, por iniciativa de loannis Ketseas e Carl Diem que a apresentaram, em primeira mão ao Comité Olímpico da Grécia, para posteriormente ser apresentada ao COI no decorrer da sua 38. ${ }^{a}$ Sessão realizada no Cairo. A partir desse momento, a ideia da criação da Academia Olímpica Internacional foi sendo analisada, discutida e delineada no decorrer das 39. ${ }^{a}, 41$. $^{a}$ e 44. ${ }^{a}$ Sessões do COI, realizadas nos anos de 1939, 1947 e 1949, para a 14 de junho de 1961 ser oficialmente criada e inaugurada, em Olímpia, na Grécia, com a realização da sua primeira Sessão Internacional. Desde então, a AOI tem realizado anualmente diversas Sessões Internacionais dirigidas a jovens, educadores e dirigentes de Comités Olímpicos e Academias Olímpicas Nacionais, no sentido de propagar o Olimpismo e aumentar o conhecimento e a conscientização das pessoas dentro do Movimento Olímpico que são responsáveis e desempenham um papel importante na educação dos jovens. Para além destas iniciativas destacam-se a realização de variadas conferências e seminários, para mais recentemente, em 2009, em parceria com a Universidade do Peloponeso, organizar o Programa de Mestrado Internacional sobre "Estudos Olímpicos, Educação Olímpica, Organização e Gestão de Eventos Olímpicos". (AOI, 2019).

Ao longo do tempo o COI tem colocado bastante atenção na promoção da educação, através da realização de diversas iniciativas de onde se podem referir a publicação de vários livros, a realização de conferências e a constituição de comissões para se debruçarem sobre este tipo de temáticas. Destacam-se destas iniciativas, a existência do riquíssimo Centro de Estudos Olímpicos (Olympic Studies Centre) e do Arquivo Histórico do COI, ambos localizados em Lausanne, junto ao Museu Olímpico, constituindo assim um polo de enorme disseminação de conhecimento olímpico para todo o mundo. O próprio Museu Olímpico (TOM The Olympic Museum) tem disponível uma série de recursos sobre Educação Olímpica para professores, incluindo brochuras, pósteres e várias exibições que contêm kits específicos para as escolas. (Doll-Tepper, 2011, p.3).

Por seu lado, o Comité Olímpico Internacional assume que não fica satisfeito por ter (apenas) mais crianças e jovens a assistir e a acompanhar os Jogos Olímpicos. É necessário encontrar formas de "tirar essas crianças do sofá" assumindo que apenas as que praticam desporto, poderão um dia, tornarem-se atletas, outras atletas de alto rendimento e, uma parte mais seletiva poderá tornar-se Atletas Olímpicos. Da mesma forma, o COI entende que apenas crianças que praticam desporto ou se exercitam podem desfrutar dos valores educativos e de saúde transmitidos pelo desporto. Dessa forma uma das missões assumidas pelo atual presidente do COI, Thomas Bach, é inspirar as crianças e os jovens de todo o mundo, através de um melhor acesso às práticas desportivas independentemente de onde se encontrem essas crianças e jovens. (COI, 2016, p.8).

Foi com este entendimento que o COI criou o Programa de Educação em Valores Olímpicos (OVEP), cuja primeira fase de implementação, também designada como fase piloto, decorreu entre os anos de $2005 \mathrm{e}$ 2010. Este Programa surgiu assim com o objetivo de ajudar a orientar as crianças e os jovens, através do 
desenvolvimento de ferramentas educativas adequadas para os envolver e capacitar, através da sua participação em atividades que incluem a vivência dos Valores Olímpicos da Excelência, Amizade e Respeito. Atualmente, com a implementação da 2. ${ }^{a}$ fase, o OVEP está a ser implementado em mais de 110 países, entre os quais se encontra Portugal. O Programa apresenta um conjunto bastante alargado de temas e propostas de atividades que garantem, por parte dos educadores e professores uma transmissão de conhecimentos e competências uniforme, que sendo independentes do país e da realidade em que se encontram, permitem uma adaptação à situação local, desafiando milhares de jovens a experimentarem os Valores Olímpicos em ação. (COI, 2016, p.8).

Ainda de acordo com o Presidente da Comissão de Educação Olímpica do COI, o OVEP vem contribuir para: (i) tornar o ensino mais pertinente, significativo e fornecer um ambiente de aprendizagem divertido; (ii) enriquecer os materiais educativos existentes, incorporando uma abordagem de "aprender a fazer"; (iii) desenvolver habilidades para a vida dentro e fora da sala de aula; e (iv) moldar o bem-estar dos jovens por meio do desporto, da atividade física, do jogo e de valores de vida. (COI, 2016, p.9).

Verificamos assim que o OVEP se encontra alinhado com a visão definida pelo COI de "construir um mundo melhor através do desporto" (COI, 2020), com a utilização de uma abordagem de ensino baseada nas tradições Olímpicas e nos valores desportivos positivos com vista ao ensino de habilidades para a vida e adoção de estilos de vida saudável. Os materiais desenvolvidos no âmbito do OVEP têm assim como objetivo enriquecer os materiais educativos já existentes em cada país e, desta forma, ajudar a melhorar 0 desempenho académico dos alunos e a sua responsabilidade cívica, através da realização de diversas atividades propostas.

Com as naturais adaptações e ajustes dos conteúdos às realidades locais, que já foram previamente referidas, há, no entanto, uma característica que sobressai na implementação dos Programas de Educação Olímpica. Estamos a referirmo-nos à sua transversalidade e metodologia pró-ativa, com uma liberdade temática, contrária à abordagem unilateral geralmente característica do ensino tradicional. Pretende-se assim, através dos Programas de Educação Olímpica estimular e promover a criatividade, a iniciativa, a experimentação e o imaginário dos professores e alunos envolvidos, através da utilização de um referencial metodológico, que possibilita o estudo em diversas disciplinas, que vão desde a Educação Física, História, Geografia, Filosofia, Biologia, Línguas, as Artes e as Tecnologias, entre outras. (Georgiadis, 2010, p.6714; COP, 2020).

\section{MATERIAIS E METODOLOGIA}

Este é um trabalho de análise documental baseado na identificação e seleção de fontes bibliográficas existentes na área da Educação Olímpica e de Programas de Educação Olímpica. A recolha de experiências e exemplos de boas práticas implementados por outros Comités Olímpicos nacionais e Comités Organizadores de Jogos Olímpicos, permitiram a criação de um Programa de Educação Olímpica em Portugal, que será apresentado ao longo deste trabalho.

\section{RESULTADOS}

Foi com o mote da "Valorização da dimensão social e educativa do desporto e do Olimpismo" que o Comité Olímpico de Portugal idealizou a criação de um Programa de Educação Olímpica (PEO). Com este objetivo traçado em 2015, deu-se início à identificação e recolha de informações e experiências existentes noutros países. Naturalmente que a primeira fonte consultada e estudada foi o OVEP. À data, ainda com a sua 
configuração e design inicial, foi possível entender que estaríamos perante o desafio de criar um Programa de Educação constituído não só por conteúdos, mas também por um conjunto prático de recursos de aprendizagem desenvolvidos para inspirar e permitir que os jovens experimentassem os valores da vida, através dos Valores Olímpicos: Excelência, Amizade e Respeito. Assim e utilizando esta recolha de informações, como as nossas "fontes de inspiração" podemos afirmar que o OVEP, constituído por conteúdos desenvolvidos por um conjunto de especialistas em matérias de Educação e de Olimpismo sob a orientação e direção do Comité Olímpico Internacional, foi a nossa primeira grande inspiração, que nos permitiu desde o primeiro momento definir um conjunto de linhas orientadoras do que deveria ser o Programa de Educação Olímpica a implementar em Portugal.

Como segunda fonte de inspiração tivemos o programa de educação desenvolvido e implementado pelo Comité Organizador dos Jogos Olímpicos e Paralímpicos Rio 2016: Transforma. Este Programa teve como grande vantagem o facto de estar desenvolvido em língua portuguesa e o Brasil ser um país de estreitas relações com Portugal, facto que permitiu que o Transforma fosse apresentado a 18 de maio de 2015, por Leonardo Gryner, Diretor Geral da Comissão Organizadora dos Jogos Olímpicos e Paralímpicos do Rio 2016, na sede do Comité Olímpico de Portugal. Este Programa, implementado em parceria com 423 Escolas do Ensino Fundamental e Médio, tinha como objetivo criar oportunidades para os cerca de 275000 estudantes vivenciarem os Valores Olímpicos e Paralímpicos, experimentarem novas modalidades desportivas e criarem uma 'ligação' aos Jogos através do material didático produzido, dos cursos de formação sobre a metodologia a usar e dicas de atividades multidisciplinares a serem implementadas e desenvolvidas pelos professores nas Escolas.

Desta forma, com os recursos existentes, a maioria deles em formato digital e disponíveis para consulta online, foi possível enriquecer e robustecer a idealização dos temas centrais que gostaríamos de começar a disponibilizar e promover junto dos professores através da criação de uma rede de Estabelecimentos de Ensino. O facto de estarmos em vésperas da realização dos Jogos Olímpicos Rio 2016 também proporcionou esta 'aproximação' entre países, e a partilha de recursos e experiências foi sem dúvida um fator de sucesso para Portugal dar os primeiros passos na promoção e implementação de um Programa de Educação Olímpica.

Naturalmente que temos também de identificar outros Programas de Educação Olímpica que nos deram a oportunidade de aprender e incluir características e aspetos que se adequavam à cultura portuguesa e aos objetivos que pretendíamos alcançar. Exemplos como o "Get Set" desenvolvido pela British Olympic Association e Bristish Paralympic Association, o "A.S.P.I.R.E." criado pelo Comité Olímpico da Austrália e 0 "COSP - Canadian Olympic School Program" implementado pelo Comité Olímpico do Canadá, foram os outros exemplos que nos permitiram, numa primeira fase, idealizar e definir o formato do Programa de Educação Olímpica que estava a ser criado.

É importante salientar que em Portugal, esporadicamente e muitas vezes sem o conhecimento do Comité Olímpico de Portugal, eram já organizadas algumas iniciativas de promoção dos Jogos Olímpicos e dos Valores Olímpicos. A este respeito é também importante realçar que Portugal, em conjunto com a Áustria, Bélgica, Canadá, Grã-Bretanha, Grécia, Suiça, Uruguai e Venezuela, celebraram pela primeira vez, a 23 de junho de 1948, o Dia Olímpico. Desde então estas celebrações têm feito parte, de forma regular, do Plano de Atividades do COP. Estas iniciativas, são muito provavelmente as atividades que, até à criação do Programa de Educação Olímpica, juntamente com a realização de palestras, debates, conferências, seminários e conversas com Atletas Olímpicos, tiveram como objetivo a promoção do Olimpismo e dos Valores Olímpicos. 
Chegou o dia em que a ideia estava estruturada e era preciso passar à ação. Foram criados inicialmente quatro manuais sobre os temas: Olimpismo, Os Símbolos Olímpicos, a Mascote e a Marca, e Os Jogos Olímpicos, assim como, pósteres e postais dos Valores Olímpicos utilizando imagens de Atletas Olímpicos portugueses. Fez-se uma consulta de mercado para se selecionar a empresa que viesse a desenvolver a plataforma online do PEO: http://www.eduolimpica.comiteolimpicoportugal.pt/ que ao longo do tempo tem sido melhorada e atualizada e testou-se uma fase piloto com duas Escolas, uma de Lisboa e outra em Ovar.

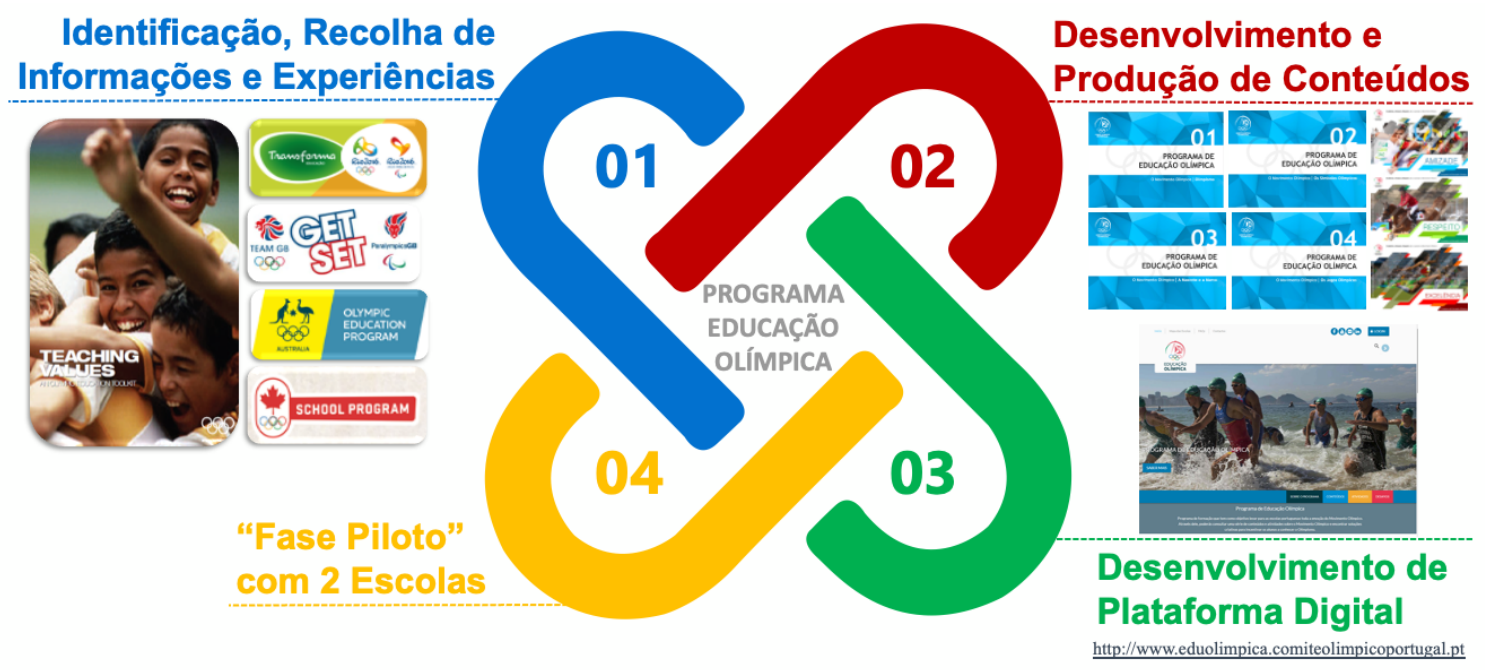

Fonte: Imagem elaborada por Rita Nunes.

Figura 1. Processo de Criação do Programa de Educação Olímpica em Portugal.

A fase piloto foi realizada para testar os materiais produzidos, a plataforma online e o trabalho com as duas Escolas permitiu-nos fazer os ajustes e as correções necessárias para que, no ano de 2016 o PEO iniciasse a sua fase de crescimento e implantação nacional. Este crescimento e aprendizagem fez com que rapidamente nos apercebêssemos que era necessário desenvolver mais conteúdos, diversificando e aprofundando as temáticas de estudo, bem como, estruturar e disponibilizar um conjunto mais extenso de propostas de atividades, de tipologia "chave na mão" para que os professores tivessem à sua disposição propostas de atividades prontas a usar. Nesta fase foram também iniciadas várias ações de apresentação do Programa e formação inicial dos professores, para se sentirem familiarizados com a metodologia e atividades que têm à disposição a partir do momento em que integrem a Rede de Estabelecimentos de Ensino do PEO.

Seguindo o formato, sugerido pelo OVEP, o Programa está desenvolvido de uma forma transversal às diversas áreas do conhecimento, os conteúdos pedagógicos e materiais de suporte sob a forma de aulas temáticas, textos complementares, fichas de atividades, materiais gráficos e vídeos foram desenvolvidos para poderem ser utilizados nas diversas disciplinas, como a História, Geografia, Artes, Música, Educação Física, Línguas, Ciências, Matemática, etc.

Ao nível das atividades, no âmbito do PEO são sugeridos vários trabalhos e desafios a realizar em contexto de sala de aula, mas também são sugeridas palestras ou aulas temáticas, iniciativas com a presença de Atletas Olímpicos, a experimentação de diversas modalidades desportivas e visitas à sede do Comité Olímpico de Portugal. 


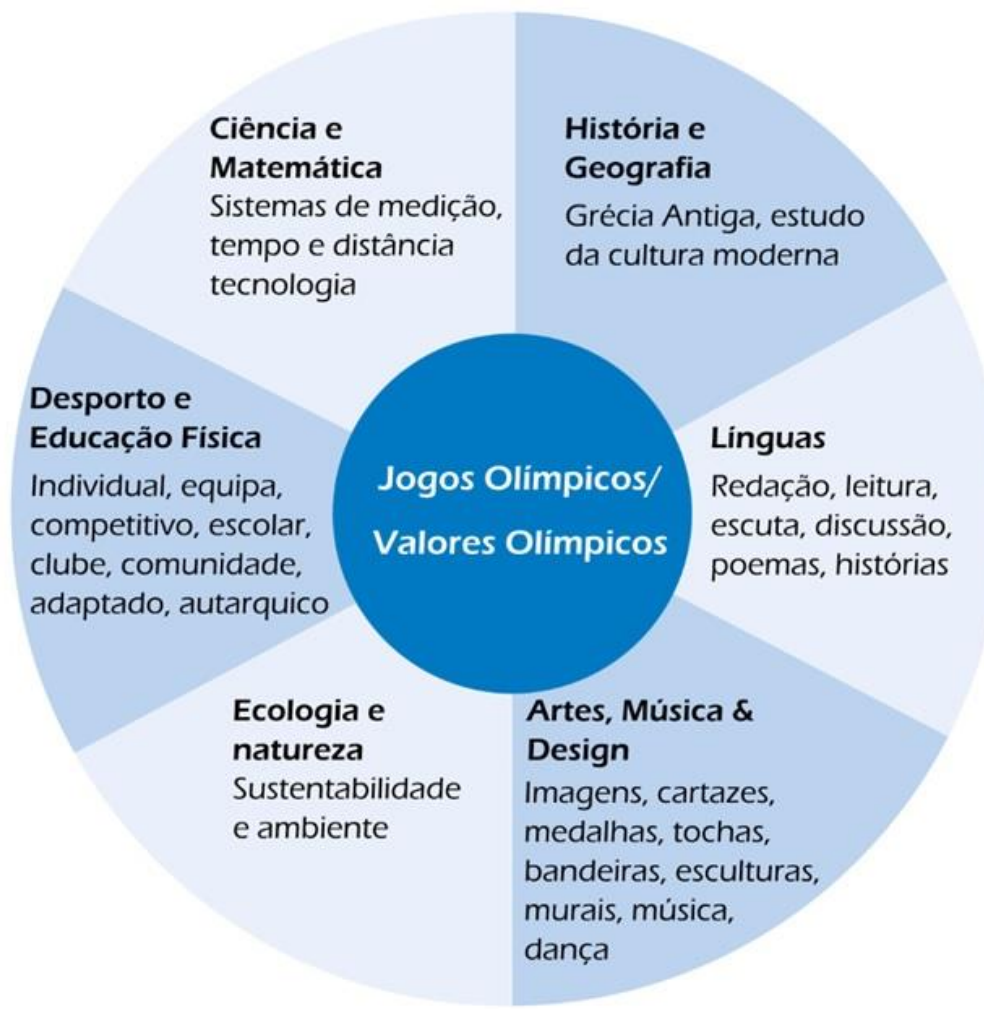

Fonte: Imagem do Programa de Educação Olímpica adaptada do OVEP (COI, 2016b, p.20).

Figura 2. Estrutura de Ensino do Programa de Educação Olímpica.

Para além da implementação do Programa de Educação Olímpica em território nacional a equipa do COP, que está diretamente responsável pela área de Educação Olímpica, tem tido oportunidades de frequentar cursos de formação nacionais e internacional com vista a aumentar os seus conhecimentos e competências, assim como, partilhar o processo de idealização e implementação do Programa de Educação Olímpica com a participação em Sessões da Academia Olímpica Internacional e lecionado Aulas em contexto de Universidades e Escolas Superiores, em Portugal e no estrangeiro. Ao nível da formação, destacam-se as participações nos Cursos de Formação Internacional "Olympism for Values Education" realizado de 3 a 11 de novembro de 2017 e "Values Education Through Sport: Applying OVEP 2.0 Methodology", de 27 de janeiro a 4 de fevereiro de 2020, ambos organizados pelo Comité Olímpico da Lituânia, no âmbito de projetos europeus financiados pelo Programa Erasmus+ Youth.

Com o aumento de Estabelecimentos de Ensino aderentes, de norte a sul de Portugal continental e regiões autónomas da Madeira e dos Açores e um crescimento muito significativo de professores, de diferentes níveis de ensino, registados no PEO, identificou-se a necessidade de aumentar o número de temáticas existentes. Assim, foram desenvolvidos e disponibilizados um total de 14 manuais, agrupados em quatro áreas complementares: O Movimento Olímpico, Os Jogos Olímpicos, A participação Portuguesa e Modalidades. É importante também referir que os conteúdos que integram o PEO estão validados pela Direção-Geral de Educação. A completar este conjunto de conteúdos foi ainda desenvolvido um "Glossário de Termos Olímpicos" que tem um objetivo uma utilização transversal a todos os intervenientes do Movimento Olímpico em Portugal, procurando-se assim que todas as pessoas conheçam e saibam utilizar 
a terminologia correta. Foram ainda desenvolvidas novas imagens para os pósteres e postais dos Valores Olímpicos.

\section{DISCUSSÃO E CONCLUSÕES}

O Programa de Educação Olímpica que tem vindo a ser implementado em Portugal, desde 2015, apresenta um crescimento bastante interessante no que se refere ao número de Estabelecimentos de Ensino aderentes e de professores registados, oriundos das diferentes áreas de ensino. No final do mês de novembro de 2020, são 678 os/as professores/as que desenvolvem as suas atividades diárias recorrendo a matérias relacionadas com a Educação Olímpica, representado um total de 231 Estabelecimentos de Ensino público e privado, que lecionam aulas desde $01 .^{\circ}$ Ciclo do Ensino Básico ao Ensino Superior.

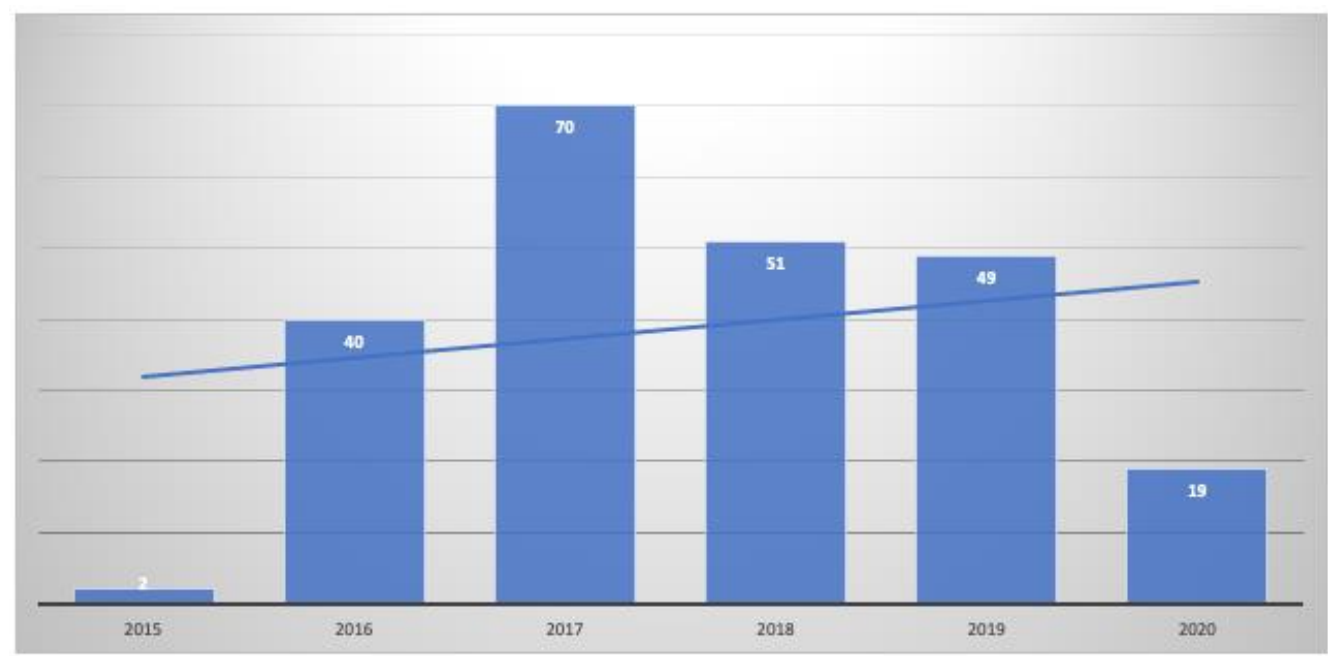

Fonte: Dados estatísticos do PEO. Imagem elaborada por Rita Nunes.

Figura 3. Evolução do número de Estabelecimentos de Ensino no PEO (2015-2020).

Os dados mostram-nos que após a fase piloto (2015) existiu um crescimento acentuado nos dois primeiros anos de implementação do PEO. Este crescimento foi fruto de várias ações de promoção e divulgação realizadas junto de vários parceiros, nomeadamente Municípios e Agrupamentos de Escolas. Tendo em conta a limitação de recursos afetos ao Programa, e por forma a manter a capacidade de resposta e a qualidade das iniciativas, estas ações de promoção foram minimizadas. Desde 2018 o crescimento tem sido mais regular, numa média de 50 Estabelecimentos de Ensino por ano, decorrentes, na maioria das vezes, de solicitações de adesão requeridas ao COP. Em 2020, e utilizando os dados existentes até ao final do mês de novembro, verifica-se um decréscimo de cerca de $60 \%$ comparativamente com os anos anteriores, naturalmente justificado pela situação pandémica que o país vive desde meados de março.

Apesar de existir, em termos gerais, uma abrangência do território nacional, verifica-se uma maior concentração de Estabelecimentos de Ensino que aderiram ao PEO na faixa litoral de Portugal continental, localizando-se principalmente junto das cidades que apresentam maior densidade populacional. A esta assimetria territorial será dada nos próximos tempos uma atenção especial, na tentativa de a colmatar e proporcionar uma igualdade de oportunidades aos alunos que frequentam os estabelecimentos de ensino das regiões do interior e ilhas. 


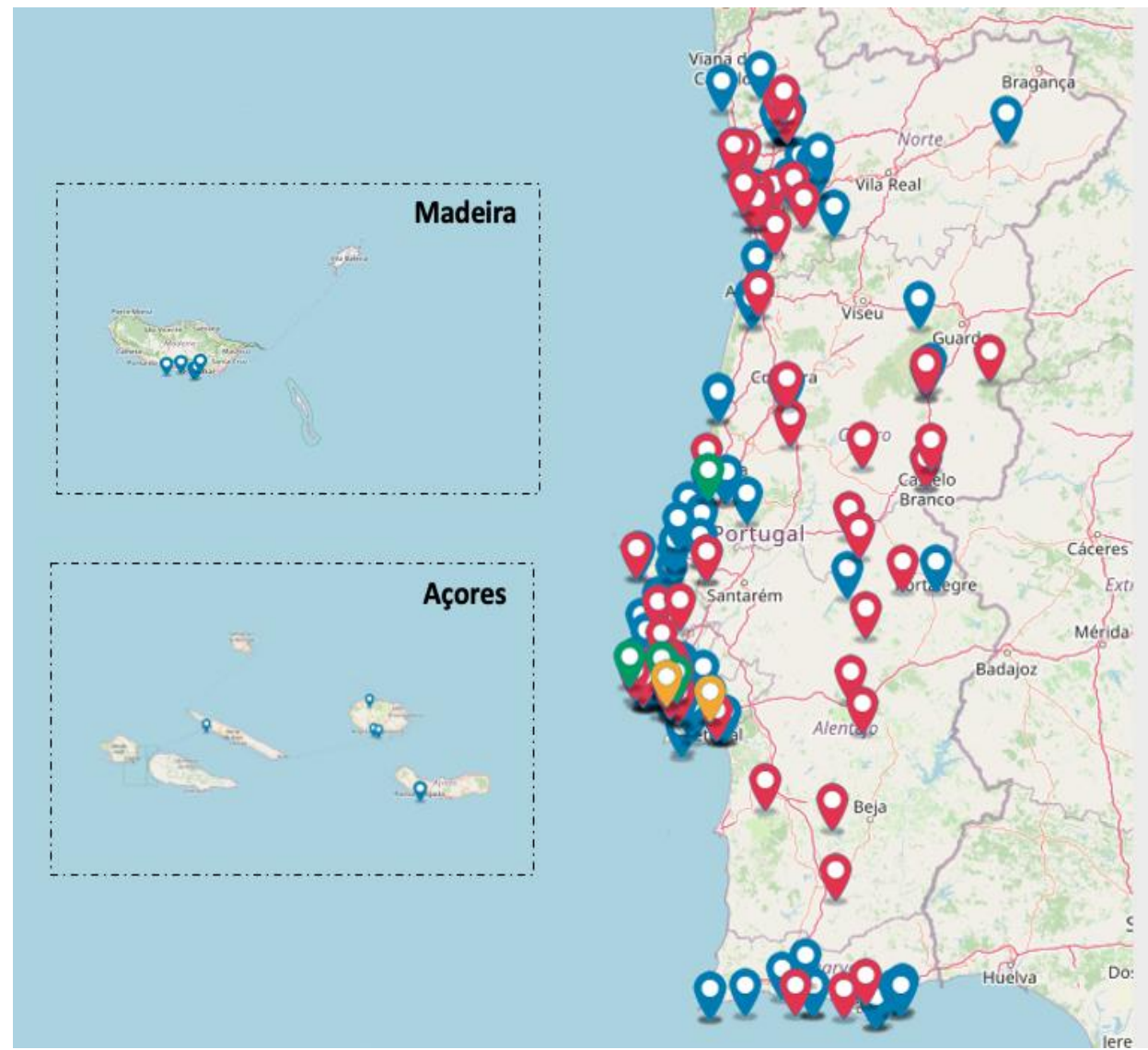

Fonte: Comité Olímpico de Portugal (COP, 2020).

Figura 4. Mapa de Estabelecimentos de Ensino que integram o PEO.

Decorrente da pandemia COVID-19 pode considerar-se que o ano de 2020 é um ano atípico. Atrevemo-nos mesmo a dizer que 0 ano 2020, face aos constrangimentos apresentados, nos lançou novos desafios, sobre os quais tentámos criar oportunidades de melhoria, evolução e crescimento. A este respeito é necessário referir que, em Portugal, as atividades letivas a partir de meados de março se transformaram num modelo de ensino à distância $(E @ D)$ para o qual a grande maioria dos professores e estabelecimentos de ensino não estavam preparados. Em meados de setembro iniciou-se o ano letivo de 2020/2021, que apesar de estar a ser realizado em formato presencial, trouxe um conjunto enorme de normativos e contingências aos alunos, professores e à própria dinâmica e organização das aulas.

Foi com esta situação pandémica, vivida de uma forma global, que iniciámos uma reestruturação do PEO, tornando-o mais acessível, mais digital e com recurso a um maior uso das tecnologias, para desta forma podermos continuar a colaborar e a dar respostas às solicitações apresentadas pelos professores e estabelecimentos de ensino. Começámos assim por reformular e desenvolver mais conteúdos programáticos do PEO, todos eles em formato digital, com uma imagem mais moderna e dinâmica. A este propósito realçamos o facto desta versão 2.0 dos conteúdos ter sido apresentada e disponibilizada à comunidade escolar no dia 23 de junho, dia de celebração do Dia Olímpico.

Ainda a este respeito, note-se que as celebrações do Dia Olímpico 2020 que estavam previstas para se realizarem em várias localidades do país e dinamizadas em conjunto com diversos parceiros, foram também 
elas reformuladas para se concretizarem num formato $100 \%$ digital, implementando-se também em Portugal, as orientações do COI, com a realização da campanha \#StayStrong \#StayHealthy\#StayActive que decorreu de 15 a 23 de junho, com a publicação diária de três conteúdos digitais desenvolvidos com a colaboração dos Atletas Olímpicos portugueses. (COP, 2020).

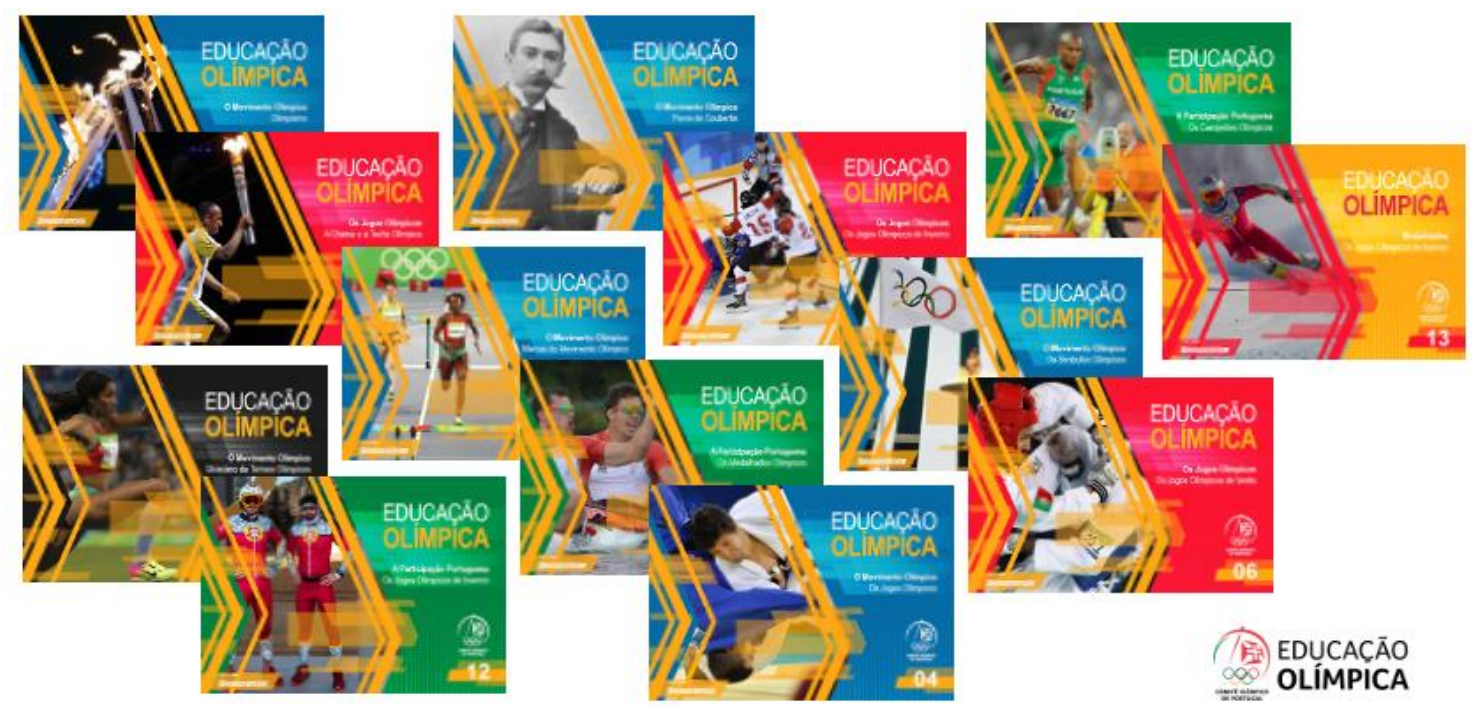

Fonte: Imagem do Programa de Educação Olímpica (COP, 2020).

Figura 5. Conteúdos pedagógicos do PEO - Edição 2.0.

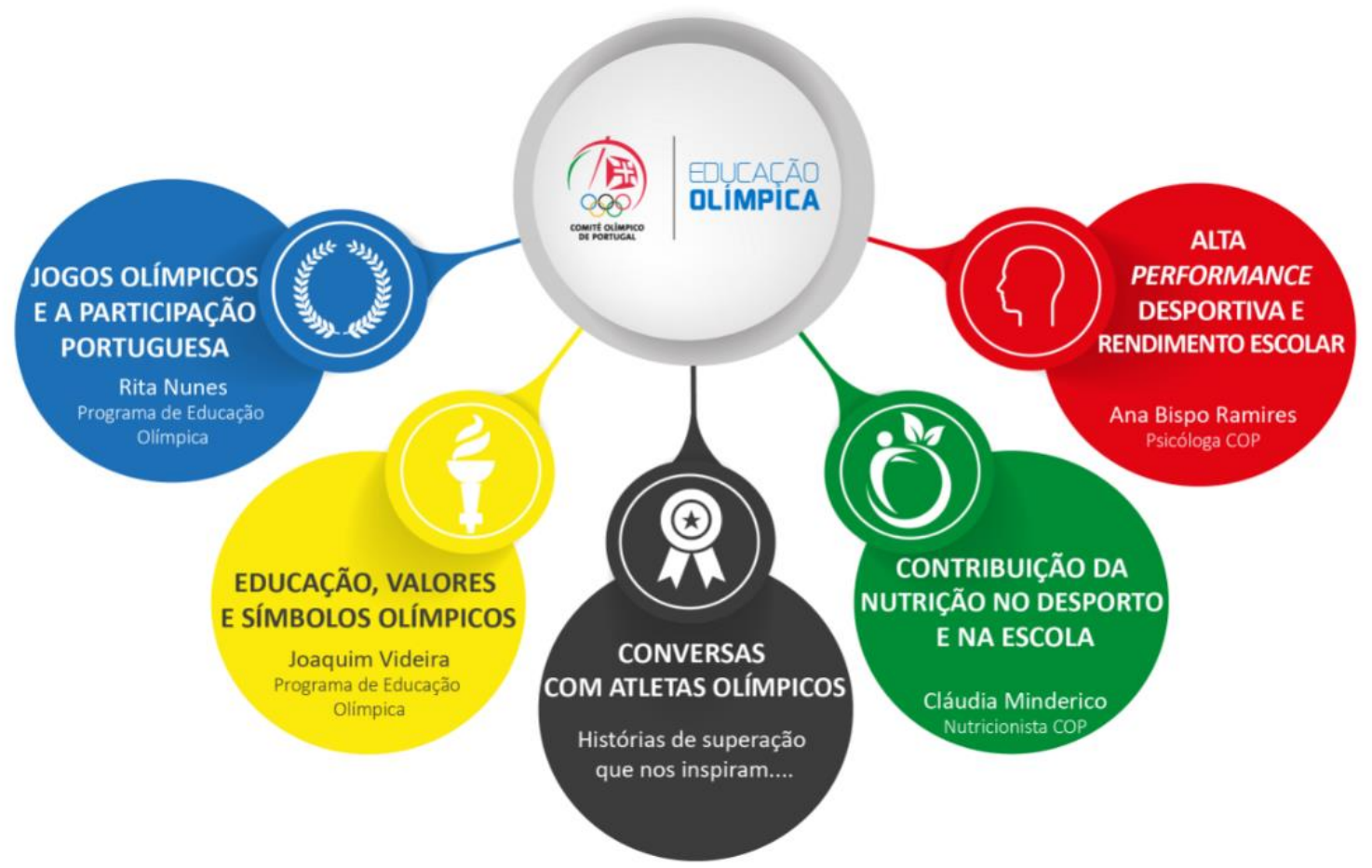

Fonte: Imagem do Programa de Educação Olímpica (COP, 2020).

Figura 6. Atividades do PEO "À distância de um clique". 
Decorrente da adaptação do PEO ao digital, foi também lançado um conjunto mais alargado de propostas de atividades, numa abordagem que designamos de "à distância de um clique". Desta forma foram desenvolvidos conteúdos, agrupados em cinco grandes áreas temáticas: Jogos Olímpicos e Participação Portuguesa; Educação, Valores e Símbolos Olímpicos; Alta Performance Desportiva e Rendimento Escolar; Contribuição da Nutrição no Desporto e na Escola e, Conversas com os Atletas Olímpicos, num formato de aulas temáticas, com duração de 30 a 45 minutos, lecionadas a partir de uma plataforma online por especialistas das diferentes áreas.

Ainda relacionado com os novos desafios que os Professores e os Estabelecimentos de Ensino enfrentam neste ano letivo de 2020/2021, foi realizado a 12 de outubro, o primeiro Webinar do PEO designado "Novos Desafios, Novas Abordagens" que contou com a presença de 110 professores. Nesta sessão, para além de terem sido apresentadas as novas abordagens que o Programa disponibiliza, agora com conteúdos mais ágeis e dinâmicos que os professores podem utilizar no dia-a-dia, foi também abordado o tema da otimização de competências, as competências emocionais do Professor, a gestão energética e o papel e importância do professor na facilitação da aquisição de competências e saberes.

Independentemente de estarmos a viver uma situação inesperada com impactos em todos os quadrantes da sociedade, todos nós, adequando os nossos hábitos diários e seguindo as recomendações oriundas das autoridades de saúde e governamentais, estamos diariamente a dar o nosso melhor para que o mundo regresse rapidamente à normalidade. É nesta perspetiva que o trabalho realizado no âmbito do Programa de Educação Olímpica tem vindo a ser ajustado e desenvolvido face aos novos desafios. Estamos certos que, em vésperas da realização dos Jogos Olímpicos de Tóquio, entretanto adiados para o verão de 2021, os Estabelecimentos de Ensino, os Professores e os Alunos demonstrarão ainda mais curiosidade e vontade de conhecer mais o Movimento Olímpico, os Jogos Olímpicos e os atletas que estarão em Tóquio para se superarem e alcançarem os seus objetivos. Neste sentido acreditamos que este ano letivo de 2020/2021 será um ano importante para a consolidação do PEO em Portugal e que, com a aproximação aos Jogos Olímpicos haja também um aumento do número de Estabelecimentos de Ensino a integrarem o Programa e um maior número de Professores registados e a utilizar os recursos disponíveis, para que mais alunos possam vivenciar atividades e iniciativas de Educação Olímpica.

\section{REFERÊNCIAS}

AOI. (2019). Portal da Academia Olímpica Internacional. Retrieved from: https://ioa.org.grlioa-throughtimel

Binder, D. (2009), Teaching Olympism in Schools: Olympic Education as a Focus on Values Education. Centre d'Estudis Olímpics. Barcelona: Universitat Autónoma de Barcelona (CEO-UAB). Retrieved from: https://ddd.uab.cat/pub/worpap/2010/181092/binder_eng.pdf

Cardoso C. P. (1996), Os Jogos Olímpicos. The Olympic Games, Lisboa, Portugal: CTT Correios de Portugal.

CEO (2020). Portal da Olympic World Library. Zoom in. Olympic Education. The Olympic Studies Centre. Retrieved from: https://library.olympic.org/default/education-olympique.aspx

Chatziefstathiou D. \& Henry P. (2012). Discourses of Olympism. From the Sorbonne 1894 to London 2012, London, UK: Palgrave Macmilan. https://doi.org/10.1057/9781137035561

COI. (2018). Factsheet. Olympic Values Education Programme (OVEP). Retrieved from: https://stillmed.olympic.org/media/Document\%20Library/OlympicOrg/Factsheets-ReferenceDocuments/OVEP/Factsheet-Olympic-Values-Education-Programme-OVEP-January2018.pdA\# ga=2.159561723.757569108.1568726049-711311674.1568726049 
COI. (2020). Portal do Comité Olímpico Internacional. Retrieved from: https://www.olympic.org/aboutioc-olympic-movement

COP. (2020). Portal do Programa de Educação Olímpica do Comité Olímpico de Portugal. Retrieved from: http://www.eduolimpica.comiteolimpicoportugal.pt/Pages/SobrePrograma.aspx

Doll-Tepper G. (2011). The Relevance of Olympic Education in Today's Societies, Countries and School Programme. Documento escrito no âmbito da reunião Comité de Seleção de Bolsas de PósGraduação do Centro de Estudos Olímpicos do Comité Olímpico Internacional. Retrieved from: https://library.olympic.org/Default/doc/SYRACUSE/161878

Ferreira A., DaSilva F. \& Afonso R. (1996). Jogos Olímpicos. Um Século de Glória. Atenas 1896 - Atlanta 1996, Matosinhos, Portugal: Quidnovi.

Georgiadis K. (2010). The Implementation of Olympic Education Programs at World Level. Procedia Social and Behavioral Sciences, 41, pp.6711-6718. https://doi.org/10.1016/..sbspro.2010.05.017

International Olympic Committee (2014). Olympic Agenda 2020: 20+20 Recommendations. Lausanne, Switzerland: International Olympic Committee.

International Olympic Committee (2016). Delivering OVEP. A Practical Guide to Olympic Values Education. (2nd ed.). Lausanne, Switzerland: International Olympic Committee.

International Olympic Committee (2020b). Olympic Charter. In force as from 17 July 2020. Lausanne, Switzerland: International Olympic Committee. Retrieved from: https://www.olympic.org/documents/olympic-charter

International Olympic Committee. (2016b). The Fundamentals of Olympic Education. A Sports-Based Programme. (2nd ed.). Lausanne, Switzerland: International Olympic Committee.

Lópes J. R. (2008). Historia del deporte, (tercera edición). Barcelona, Espanha: INDE Publicaciones. MacAloon J. J. (2008). This Great Symbol. Pierre de Coubertin and the Origins of the Modern Olympic Games. New York, NY: Routledge.

Monnin E. (2020). The implementation of the Olympic education concept through "Generation 2024". University of Franche-Comté. Retrieved from: https://library.olympic.org/doc/SYRACUSE/470519

Morath P. (2012). The Villa Mon-Repos and the Olympic Movement. A Century of Olympic Presence in Lausanne. Lausanne: Olympic Solidarity and City of Lausanne.

Muller N. (2010). Olympic education. Centre d'Estudis Olimpics. Barcelona: Universitat Autònoma de Barcelona (CEO-UAB). Retrieved from: https://ddd.uab.cat/pub/caplli/2010/181093/muller_eng.pdf

Naul, R., Binder, D., Rychtecky A. \& Culpan I. (Edi.). (2017). Olympic Education. An International Review. (4th ed.). New York, NY: Routledge. https://doi.org/10.4324/9780203131510

Nunes R. \& Videira J. (2020). Educação Olímpica. Olimpismo. O Movimento Olímpico. (2. ${ }^{a}$ edição). Lisboa, Portugal: Comité Olímpico de Portugal.

\section{(9) $(\mathbb{Q} \Theta \Theta$}

This work is licensed under a Attribution-NonCommercial-NoDerivatives 4.0 International (CC BY-NC-ND 4.0). 